\title{
Antihyperglycaemic and Antihyperlipidaemic Activities of Ethanol Leaf Extract of Eleusine coracana (Linn.) Gaertn. in Alloxan-Induced Hyperglycaemic Rats
}

\author{
Abdullahi Hamza Yaro*, Musa Aliyu, Safiya Bala Borodo, Abdullahi Balarabe Nazifi \\ Department of Pharmacology and Therapeutics, Bayero University Kano, Nigeria.
}

\begin{tabular}{l}
\hline ARTICLE INFO \\
\hline Article history: \\
Received on: 22/01/2018 \\
Accepted on: 08/06/2018 \\
Available online: $30 / 07 / 2018$
\end{tabular}

Key words:

Diabetes mellitus, Eleusine

coracana, Hyperglycaemia,

Hyperlipidaemia.

\begin{abstract}
The importance of Eleusine coracana against diabetes mellitus is documented in the literature. The effectiveness of its leaf extract against diabetes is highly praised among the rural people of northern Nigeria. In this study, we examined the antihyperglycaemic and antihyperlipidaemic potentials of E. coracana leaf extract (ECE) in alloxaninduced hyperglycaemic Wistar rats. Phytochemical screening of ECE was carried out as well as the oral median lethal dose $\left(\mathrm{LD}_{50}\right)$ determination in rats. Hyperglycaemia was produced in rats by injecting alloxan monohydrate (130 $\mathrm{mg} / \mathrm{kg}$ ) intraperitoneally. The ECE at oral doses of 250,500 and $1000 \mathrm{mg} / \mathrm{kg}$ were administrated once daily to the hyperglycaemic rats for 14 days. The effect of ECE on fasting blood glucose levels, body weight, total cholesterol (TC), triglycerides (TG), high-density lipoprotein (HDL) and low-density lipoprotein (LDL) were measured and analyzed. Phytochemical tests showed the presence of alkaloids, phenols, flavonoids, tannins, terpenoids, saponins and cardiac glycosides while the oral $\mathrm{LD}_{50}$ was $>5000 \mathrm{mg} / \mathrm{kg}$. Administration of ECE significantly $(p<0.05)$ decreased the blood glucose levels compared to the hyperglycaemic control rats at different time intervals, while the body weights were significantly $(p<0.05)$ increased. Alloxan administration resulted in significant $(p<0.05)$ elevation of LDL, TG, TC and decline in HDL levels when compared to normal rats. However, ECE significantly $(p<0.05)$ decreased the LDL, TG and TC levels, and increased the HDL levels of the hyperglycaemic rats. In conclusion, the results suggest that ethanol leaf extract of E. coracana possesses antihyperglycaemic and antihyperlipidaemic properties.
\end{abstract}

\section{INTRODUCTION}

Diabetes mellitus is a chronic metabolic disease characterized by raised blood glucose levels, which leads over time to significant impairment to the heart, kidneys, eyes, blood vessels and nerves (WHO, 2016). It is categorized seventh, among the important causes of death globally and it is considered third when its complications are taken into account (Trivedi et al., 2004). Diabetes mellitus is associated with wide range of diseases including diabetic nephropathy (Lee et al., 2014), liver diseases (Leeds et al., 2009), coronary heart disease and ischaemic stroke (Spencer et al., 2008). The conventional antidiabetic drugs are associated with serious side effects which affect the blood, liver,

${ }^{*}$ Corresponding Author

Abdullahi Hamza Yaro, Department of Pharmacology and Therapeutics, Bayero University, P.M.B. 3011, Kano, Nigeria.

E-mail: ahyaro.pha@buk.edu.ng and kidney (Hellmuth et al., 2000), while some of the drugs are not able to control some complications like hyperlipidaemia. These shortcomings have led to the increased patronage of alternative therapies like herbal medicine.

The use of natural products from herbs forms an important component of the health care delivery system in African countries (Cragg and Newman, 2013). Researches on medicinal plants have led to the discovery of novel lead compounds for potential development as drugs that function on new or established therapeutic targets (Ramírez-Espinosa et al., 2011). Herbal products are extensively used in the management of diabetes mellitus and recently there is a renaissance of interest in medicinal plants with antihyperglycaemic potential (Mamun-orRashid et al., 2014). One of such plants widely used in Nigeria in the management of diabetes mellitus is Eleusine coracana.

Eleusine coracana (Linn.) Gaertn., a member of Poaceae family is an erect tufted annual grass that is cultivated extensively 
across Africa and throughout tropical Asia. It is commonly known as English finger millet or African millet (Burkill, 1985). The vernacular names include "Tamba" (Hausa), "Chargari" (Fulfulde) and "Oka tamba" (Igbo). E. coracana is utilized in ethnomedicine for the management of a range of disease conditions including dysentery and diabetes (Burkill, 1985). The health benefits of $E$. coracana polyphenols and dietary fiber is well documented (Devi et al., 2014). The leaves are consumed as vegetables and as a traditional remedy for leprosy, urinary tract infection and diabetes mellitus (Chandrashekar, 2010), while the seeds are important source of cereal foods recommended for diabetics (Shobana et al., 2009).

Previous scientific reports have shown that administration of E. coracana whole meal-incorporated diet reduced the blood glucose levels of alloxan-induced hyperglycaemic rats (Hegde et $a l ., 2005)$. Phenolic acids extracted from milled fractions of finger millet possess antioxidant and antimicrobial activities (Viswanath et al., 2009). The seed coat matter has also been reported to ameliorate hyperglycaemic and its associated complications like hypercholesterolaemia (Shobana et al., 2009). Despite the wide usage of E. coracana leaf extract in herbal medicine against diabetes mellitus, there is no scientific statement on the antihyperglycaemic and antihyperlipidaemic properties of the leaf extract of the plant. Therefore, this study was carried out to investigate the antihyperglycaemic and antihyperlipidaemic potentials of the ethanol leaf extract of E. coracana in alloxan-induced hyperglycaemic rats.

\section{MATERIALS AND METHODS}

\section{Animals}

Male rats weighing 120-200 g, were acquired from the animal house facility of the Department of Pharmacology and Therapeutics, Ahmadu Bello University, Zaria. The rats were kept in properly ventilated plastic cages at room temperature and provided with standard laboratory animal food and water ad libitum. They were treated in accordance with the National Institute of Health (NIH) Guide for the Care and Use of Laboratory Animals (Publication No. 85-23, revised, 1996) and approved institutional Research and Ethical Committee (Protocol Number: DPTAC/IVT-IVV/015-00021).

\section{Chemicals and instruments}

Ethanol (Sigma-Aldrich, Germany), Metformin (Merck Santé, France), D (+) glucose, Alloxan monohydrate (SigmaAldrich, Germany), Glucometer and test strips (ACON Lab, USA), Lipid meter and test strips (ACON Lab, USA).

\section{Plant material}

E. coracana leaves were collected from Zaria, in August 2015. They were identified and authenticated by a taxonomist, Baha'uddeen Said Adam at the herbarium unit of the Department of Biological Sciences, Bayero University, Kano, where a voucher number BUKHAN 0299 was assigned by comparing with a voucher specimen previously deposited in the herbarium as a reference.

\section{Preparation of plant extract}

The leaves of E. coracana were cleaned and dried under shade for about four weeks. They were crushed in a mortar and then sieved to obtain a fine powder. The powdered leaf (555 g) was macerated in 4 liters of $70 \% \mathrm{v} / \mathrm{v}$ ethanol in a closed container, at room temperature, with periodic shaking for 14 days. It was then filtered using a filter paper and the filtrate was transferred to an evaporating dish, where it was evaporated to dryness in an oven at $50^{\circ} \mathrm{C}$. The extract was weighed, stored in an air tight container and labeled as E. coracana extract (ECE). It was then kept in a desiccator until required for the main experiment.

\section{Phytochemical screening}

The preliminary phytochemical screening was carried out on extract to detect the presence of secondary metabolites according to the standard protocol (Evans, 2009).

\section{Acute toxicity studies}

Oral acute toxicity studies as described by Lorke (1983) were adopted. Rats were fasted for 12-16 hours before the study after which they were allowed access to water only. The study was carried out in two phases; in phase one, nine animals were divided into three groups of three rats each, and then treated orally with ethanol leaf extract of E. coracana at doses of 10, 100 and $1000 \mathrm{mg} / \mathrm{kg}$ respectively. The rats were examined for signs and symptoms of toxicity within 24 hours as well as mortality. In the second phase, three fresh rats were treated orally with 1600, 2900 and $5000 \mathrm{mg} / \mathrm{kg}$ of the extract (based on the results of phase one studies). The rats were also examined for signs and symptoms of toxicity and or mortality for 24 hours. Thereafter, the median lethal dose $\left(\mathrm{LD}_{50}\right)$ was determined by evaluating the geometric mean of the lowest lethal dose and the highest non-lethal dose.

\section{Experimental design}

The studies were conducted on six groups of seven rats each $(n=7)$. The first group of rats was normal rats (administered normal saline, $1 \mathrm{~mL} / \mathrm{kg}$ ); while alloxan-induced hyperglycaemic rats were assigned accordingly to the remaining five groups. Group II rats served as hyperglycaemic control and were administered normal saline $(1 \mathrm{~mL} / \mathrm{kg})$. Groups III, IV and V were hyperglycaemic rats treated with ECE at doses of 250, 500 and $1000 \mathrm{mg} / \mathrm{kg}$ respectively. Group VI (positive control) were hyperglycaemic rats treated with metformin $(125 \mathrm{mg} / \mathrm{kg})$. The normal saline, ECE, and metformin were administered orally and daily for 14 days.

\section{Alloxan-induced hyperglycaemic studies}

Hyperglycaemia was induced by adopting the method described by Goldner and Gomori (1944). Sixty (60) male rats were injected intraperitoneally with $130 \mathrm{mg} / \mathrm{kg}$ alloxan monohydrate diluted in citrate buffer after 14 hours of fasting. Six hours after administration of alloxan, the rats were treated with $5 \%$ glucose for the next $24 \mathrm{hrs}$ to prevent fatal hypoglycaemia that may result from the massive pancreatic release of insulin. The rats were then given access to food and water and observed for 72 hours for signs of hyperglycaemia. Thereafter, they were examined for hyperglycaemia using a one-touch glucometer with compatible strips, which follows the glucose oxidase principles (Beach and Turner, 1958). This was achieved by snipping the tail tip of each rat and subsequently squeezing the tail to obtain a drop of blood. Rats with fasting blood glucose levels $>200 \mathrm{mg} / \mathrm{dL}$ were 
selected and used for the study. The blood glucose levels were taken on day 0 (at $0,2,4,6,8$ and 24 hours), 7 and 14 . The body weights of the animals were also measured on days 0,7 and 14 .

\section{Biochemical estimations}

Triglycerides (TG), total cholesterol (TC), high-density lipoprotein (HDL) and low-density lipoprotein (LDL) levels of all the groups of rats were analyzed on days 0,7 and 14 using a onetouch lipid meter with compatible strips (ACON Lab., U.S.A.).

\section{Statistical analysis}

Data obtained were analyzed statistically using Statistical Package for Social Science (SPSS) Version 20. The differences between means were analyzed by one-way Analysis of Variance (ANOVA), and where a significant difference was obtained with ANOVA, Tukey post hoc test was carried out. Values of $p<0.05$ were considered statistically significant and the results were expressed as Mean \pm Standard Error of the Mean (S.E.M.).
The percentage yield of the ethanol leaf extract of $E$. coracana was calculated to be $13.51 \% \mathrm{w} / \mathrm{w}$. Phytochemical screening of ECE showed the presence of alkaloids, saponins, phenols, flavonoids, tannins, terpenoids and cardiac glycosides. These phytoconstituents were reported present in its seed coat (Shobana et al., 2009). Flavonoids, sterols, alkaloids, and polyphenols are secondary metabolites reported to possess antidiabetic activity (Jadeja et al., 2010). Phenolic compounds are said to be involved in the healing process of free radicalmediated diseases such as diabetes and its complications such as hyperlipidaemia (Czinner et al., 2000). They also reduce hyperglycaemia and decrease the postprandial blood glucose response in rats (Scalbert et al., 2005). Phenols isolated from cereals including E. coracana plant have also been reported to possess hypoglycaemic and hypolipidaemic properties (Tsuda et al., 2003; Hedge et al., 2005). The antihyperglycaemic and antihyperlipidaemic activities of E. coracana leaf extract as observed in this study may also be attributed to the presence of some of these bioactive principles.

\section{RESULTS AND DISCUSSION}

Table 1: Effect of single administration of Eleusine coracana extract on blood glucose levels of alloxan-induced hyperglycaemic rats.

\begin{tabular}{|c|c|c|c|c|c|c|}
\hline \multirow{2}{*}{ Treatment (mg/kg) } & \multicolumn{6}{|c|}{ Mean blood glucose levels (mg/dL) } \\
\hline & $0 \mathrm{Hr}$ & $2 \mathrm{Hr}$ & $4 \mathrm{Hr}$ & $6 \mathrm{Hr}$ & $8 \mathrm{Hr}$ & $24 \mathrm{Hr}$ \\
\hline $\mathrm{N} / \mathrm{S}(1 \mathrm{~mL} / \mathrm{kg})$ & $78.0 \pm 1.1$ & $76.0 \pm 1.5$ & $73.0 \pm 0.5$ & $75.6 \pm 1.0$ & $74.8 \pm 1.2$ & $76.0 \pm 1.7$ \\
\hline $\mathrm{H} / \mathrm{C}$ & $438.2 \pm 5.5$ & $524.6 \pm 4.5^{\#}$ & $482.4 \pm 5.2^{\#}$ & $516.0 \pm 3.3^{\#}$ & $524.7 \pm 2.6^{\#}$ & $515.4 \pm 2.5^{\#}$ \\
\hline ECE (250) & $446.0 \pm 1.7$ & $402.0 \pm 6.6^{*}$ & $242.8 \pm 8.8^{* *}$ & $231.8 \pm 7.6^{* *}$ & $225.3 \pm 3.1^{* *}$ & $221.2 \pm 6.9^{* *}$ \\
\hline ECE (500) & $437.2 \pm 1.2$ & $413.2 \pm 3.1^{*}$ & $247.8 \pm 7.4^{* *}$ & $229.8 \pm 8.5^{* *}$ & $220.6 \pm 3.7^{* *}$ & $215.8 \pm 3.5^{* *}$ \\
\hline ECE (1000) & $440.4 \pm 1.6$ & $375.4 \pm 1.5^{* *}$ & $238.6 \pm 2.1 * *$ & $213.8 \pm 4.2 * *$ & $201.5 \pm 2.9^{* *}$ & $193.0 \pm 1.8^{* *}$ \\
\hline MTF (125) & $431.2 \pm 7.9$ & $401.2 \pm 8.3^{*}$ & $362.6 \pm 6.0^{*}$ & $345.6 \pm 5.2^{*}$ & $333.1 \pm 1.8^{*}$ & $326.3 \pm 4.3^{*}$ \\
\hline
\end{tabular}

Values are Mean \pm S.E.M., ${ }^{*}=p<0.05, * *=p<0.01$ compared to H/C group, ${ }^{*}=p<0.01$ compared to N/S group - One way ANOVA followed by Tukey post hoc test, $\mathrm{n}=7, \mathrm{~N} / \mathrm{S}=$ Normal saline, $\mathrm{H} / \mathrm{C}=$ Hyperglycaemic control, $\mathrm{ECE}=$ Eleusine coracana extract, $\mathrm{MTF}=$ Metformin.

$\mathrm{LD}_{50}$ is a useful index for assessing the acute toxicity profile of a substance and is used to estimate the doses to be used for subsequent pharmacological studies (Lorke, 1983). The oral $\mathrm{LD}_{50}$ of ECE was estimated to be $>5,000 \mathrm{mg} / \mathrm{kg}$ in rats as no signs of toxicity or death were observed in the two phases of the toxicity studies. This suggests that the leaf extract is practically safe in rats when administered orally ( $\mathrm{Lu}, 1996)$. The results also agree with previous findings by Shobana et al. (2009) on the toxicity profile of $E$. coracana seed coat.

Hyperglycaemia was successfully induced in this study as indicated by the significant $(p<0.01)$ higher blood glucose levels recorded for the alloxan-induced hyperglycaemic groups during the 24 hours and throughout the 14 days of study. The administration of graded doses of $E$. coracana extract $(250,500$ and $1000 \mathrm{mg} / \mathrm{kg})$ significantly $(p<0.05)$ lowered the blood glucose levels when compared to the hyperglycaemic control rats in the 24 hours studies (Table 1). In the 14 days studies, E. coracana extract at all the doses tested produced a significant $(p<0.01)$ and dose-dependent reduction in the blood glucose levels on the $7^{\text {th }}$ and $14^{\text {th }}$ day when compared to the hyperglycaemic control group. Similarly, the standard drug (Metformin, $125 \mathrm{mg} / \mathrm{kg}$ ) significantly $(p<0.01)$ lowered the blood glucose levels (Table 2).

Alloxan is a diabetogenic agent used for inducing experimental hyperglycaemia (Goldner and Gomori, 1944). It is a toxic glucose analog that favorably accumulates in pancreatic $\beta$ cells through the glucose transporter 2 (GLUT2). In the company of intracellular thiols, especially glutathione, alloxan generates reactive oxygen species in a cyclic redox reaction along with dialuric acid (Lenz, 2008). Autoxidation of dialuric acid generates superoxide radicals, hydrogen peroxide and, in a final ironcatalyzed reaction step, hydroxyl radicals. These hydroxyl radicals are eventually responsible for the death of the pancreatic $\beta$ cells, which have a predominantly low antioxidative defense capacity, and the resulting state of insulin-dependent 'alloxan diabetes' (Lenz, 2008). Alloxan also selectively inhibits glucose-induced insulin secretion through its ability to inhibit the $\beta$ cell glucose sensor glucokinase (Lenz, 2008). The increase in blood glucose levels after alloxan administration could, therefore, be due to inhibition of glucose-induced insulin secretion or resistant states in diabetic rats (Balamurugan et al., 2014). Administration of $E$. coracana extract significantly reduced the blood glucose levels of the diabetic rats which represents a reversal in insulin resistance or an improvement in insulin release through regeneration of pancreatic $\beta$ cells. The antioxidant property of the plant extract (Hegde et al., 2005; Shobana et al., 2010) could also block the alloxan-induced generation of reactive oxygen species.

The deficiency of insulin can also result to various metabolic derangements including a reduction in body weight, polyuria, polyphagia, increased cholesterol and hypertriglyceridemia (Al-Shamaony et al., 1994; Balamurugan et al., 2014). Administration of alloxan caused significant ( $p<$ $0.05)$ body weight reduction in rats as compared to the normal 
rats on day 14 (from $137.4 \pm 2.3 \mathrm{~g}$ on day 0 to $128.8 \pm 2.3 \mathrm{~g}$ on day 14). However, administration of ECE $(250,500$ and $1000 \mathrm{mg} /$ $\mathrm{kg})$ significantly $(p<0.01)$ increased the mean body weights as observed on days 7 and 14 when compared with body weight at day 0 (Table 3 ). In diabetic rats, the observed reduction in body weight is due to increase in breaking down of proteins and fats (Balamurugan et al., 2014). The significant increase in body weight observed in the ECE treated groups as compared to the hyperglycaemic control implies preventive effect of the extract against degradation of structural proteins.

Table 2: Effect of 14-days daily administration of Eleusine coracana extract on blood glucose levels of alloxan-induced hyperglycaemic rats.

\begin{tabular}{cccc}
\hline \multirow{2}{*}{ Treatment (mg/kg) } & \multicolumn{2}{c}{ Mean Blood Glucose Levels (mg/dL) } \\
\cline { 2 - 4 } & Day 0 & Day 7 & Day 14 \\
\hline N/S (1 mL/kg) & $78.0 \pm 1.1$ & $77.4 \pm 1.6$ & $79.1 \pm 5.4$ \\
H/C & $438.2 \pm 5.2^{*}$ & $526.0 \pm 6.8^{*}$ & $496.4 \pm 8.8^{*}$ \\
ECE (250) & $446.0 \pm 1.7$ & $196.8 \pm 7.8^{* *}$ & $158.8 \pm 3.1^{* *}$ \\
ECE (500) & $437.5 \pm 1.2$ & $180.0 \pm 3.8^{* *}$ & $125.2 \pm 5.1^{* *}$ \\
ECE (1000) & $440.4 \pm 1.6$ & $153.1 \pm 3.2^{* *}$ & $103.6 \pm 3.3^{* *}$ \\
MTF (125) & $431.2 \pm 7.9$ & $250.0 \pm 8.2^{* *}$ & $211.0 \pm 2.0^{* *}$ \\
\hline
\end{tabular}

Values are Mean \pm S.E.M., ${ }^{* *}=p<0.01$ compared to $\mathrm{H} / \mathrm{C}$ group, $\#=p<0.01$ compared to N/S group - One way ANOVA followed by Tukey post hoc test, $\mathrm{n}=7, \mathrm{~N} / \mathrm{S}=$ Normal Saline, $\mathrm{H} / \mathrm{C}=$ Hyperglycaemic control, ECE = Eleusine coracana Extract, $\mathrm{MTF}=$ Metformin

Alloxan administration resulted in significant $(p<0.05)$ increase in LDL, TG, TC and decrease in HDL levels compared to normal rats as observed at different periods of the study (Table $4)$. There was a significant $(p<0.05)$ reduction in LDL, TG and TC levels of the hyperglycaemic rats treated with graded doses of E. coracana extract as comparable to the hyperglycaemic control at different intervals. However, a significant $(p<0.01)$ elevation in the HDL levels in E. coracana treated groups were observed at different periods of the study. These results indicate the extract's potent antihyperlipidaemic activity.

Table 3: Effect of 14-days daily administration of Eleusine coracana extract on body weight of alloxan-induced hyperglycaemic rats.

\begin{tabular}{cccc}
\hline \multirow{2}{*}{ Treatment (mg/kg) } & \multicolumn{3}{c}{ Mean body weights $(\mathbf{g})$} \\
\cline { 2 - 4 } & Day 0 & Day 7 & Day 14 \\
\hline N/S (1 mL/kg) & $133.0 \pm 8.6$ & $135.2 \pm 5.2$ & $134.4 \pm 8.6$ \\
H/C & $137.4 \pm 2.3$ & $132.4 \pm 2.8$ & $128.8 \pm 2.3^{*} \#$ \\
ECE (250) & $135.8 \pm 1.6$ & $140.6 \pm 1.6^{* \#}$ & $146.4 \pm 1.4^{* * \# \#}$ \\
ECE (500) & $136.2 \pm 4.3$ & $141.3 \pm 4.6^{* * \#}$ & $144.8 \pm 3.8^{* * \# \#}$ \\
ECE (1000) & $134.8 \pm 4.6$ & $142.1 \pm 2.5^{* * \#}$ & $146.7 \pm 1.6^{* * \# \#}$ \\
MTF (125) & $136.8 \pm 3.4$ & $138.6 \pm 3.5$ & $139.5 \pm 2.5$ \\
\hline
\end{tabular}

Values are Mean \pm S.E.M., $*=p<0.05, * *=p<0.01$ compared to N/S group; ${ }^{\#}=p<0.05,{ }^{\#}=p<0.01$ compared to Day $0-$ One way ANOVA followed by Tukey post hoc test, $n=7, N / S=$ Normal saline, $H / C=$ Hyperglycaemic control, $\mathrm{ECE}=$ Eleusine coracana Extract, $\mathrm{MTF}=$ Metformin.

An altered lipid profile is observed in cases of alloxaninduced hyperglycaemia (Ojiako et al., 2016). The usual lipid aberrations in diabetes mellitus are hypercholesterolemia and hypertriglyceridemia (Al-Shamaony et al., 1994). Hypertriglyceridemia classically occurs in conjunction with atherogenic small dense LDL particles and low HDL levels and is associated with increased cardiovascular risk (Subramanian and Chait, 2012). Atherosclerosis is also a fundamental consequence of long-standing diabetes and is the key cause of death in diabetics. In the present study, the elevations of LDL, TG, TC, and reduction in HDL levels exhibited by the hyperglycaemic rats could be due to the enhanced deployment of free-fatty acids from bordering adipose tissues (Al-Logmani and Zari, 2009). These lipid and lipoprotein abnormalities were significantly countered by the administration of ECE. The extract, therefore, could be useful in averting some complications associated with diabetes mellitus like atherosclerosis and coronary heart disease.

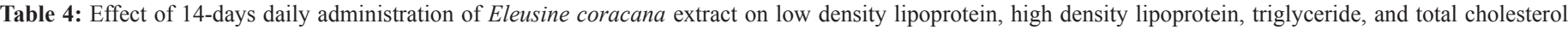
levels of alloxan-induced hyperglycaemic rats.

\begin{tabular}{|c|c|c|c|c|c|c|}
\hline \multirow{2}{*}{ Parameter } & \multirow{2}{*}{ Days } & \multicolumn{5}{|c|}{ Treatment (mg/kg) } \\
\hline & & $\mathbf{N} / \mathbf{S}$ & $\mathrm{H} / \mathrm{C}$ & ECE 250 & ECE 500 & ECE 1000 \\
\hline \multirow[t]{3}{*}{ LDL (mg/dL) } & 0 & $99.6 \pm 2.6$ & $185.0 \pm 4.3$ & $191.4 \pm 2.2$ & $191.6 \pm 2.1$ & $187.9 \pm 2.1$ \\
\hline & 7 & $100.2 \pm 2.4$ & $201.0 \pm 4.3^{*}$ & $142.0 \pm 2.3^{\# \#}$ & $140.0 \pm 1.6^{\# \#}$ & $129.4 \pm 0.5^{\ldots \#}$ \\
\hline & 14 & $98.0 \pm 2.0$ & $207.2 \pm 1.4^{* *}$ & $132.0 \pm 2.0^{\#}$ & $107.0 \pm 5.2^{\# \#}$ & $93.7 \pm 3.6^{\#}$ \\
\hline \multirow[t]{3}{*}{ HDL (mg/dL) } & 0 & $35.0 \pm 1.9$ & $27.2 \pm 2.2$ & $26.2 \pm 2.2$ & $25.9 \pm 3.3$ & $25.8 \pm 2.3$ \\
\hline & 7 & $34.3 \pm 1.2$ & $17.8 \pm 1.6^{* *}$ & $36.5 \pm 2.1^{\# \#}$ & $37.2 \pm 3.1^{\#}$ & $38.0 \pm 1.4^{\ldots \#}$ \\
\hline & 14 & $36.1 \pm 0.6$ & $19.5 \pm 2.1^{* *}$ & $38.9 \pm 1.1^{\# \#}$ & $40.2 \pm 1.4^{\# \#}$ & $42.5 \pm 1.8^{\#}$ \\
\hline \multirow[t]{3}{*}{$\mathrm{TG}(\mathrm{mg} / \mathrm{dL})$} & 0 & $111.2 \pm 36.8$ & $429.5 \pm 3.4$ & $433.8 \pm 31.6$ & $423.3 \pm 43.0$ & $432.8 \pm 6.2$ \\
\hline & 7 & $119.6 \pm 43.4$ & $451.2 \pm 3.5^{* *}$ & $380.0 \pm 38.7^{\#}$ & $310.6 \pm 9.9^{\#}$ & $295.8 \pm 5.1^{\# \#}$ \\
\hline & 14 & $118.2 \pm 30.8$ & $423.4 \pm 2.5^{* *}$ & $300.0 \pm 15.8^{\#}$ & $247.2 \pm 9.9^{\# \#}$ & $205.4 \pm 4.8^{\# \#}$ \\
\hline \multirow[t]{3}{*}{$\mathrm{TC}(\mathrm{mg} / \mathrm{dL})$} & 0 & $123.6 \pm 7.6$ & $179.0 \pm 0.9$ & $178.0 \pm 0.8$ & $179.4 \pm 2.2$ & $178.0 \pm 6.3$ \\
\hline & 7 & $123.6 \pm 7.5$ & $195.2 \pm 0.4^{* *}$ & $171.6 \pm 3.2^{\#}$ & $163.2 \pm 2.6^{\# \#}$ & $144.8 \pm 3.8^{\#}$ \\
\hline & 14 & $127.6 \pm 3.2$ & $200.6 \pm 0.2^{* *}$ & $162.6 \pm 3.2^{\# \#}$ & $155.2 \pm 4.0^{\# \# ~}$ & $121.2 \pm 5.4^{\# \#}$ \\
\hline
\end{tabular}

Values are Mean \pm S.E.M., $*=p<0.05$, $* *=p<0.01$ compared to N/S group, ${ }^{*}=p<0.05,{ }^{*}=p<0.01$ compared to H/C control group - One way ANOVA followed by Tukey post hoc test, $\mathrm{n}=7, \mathrm{~N} / \mathrm{S}=$ Normal saline, $\mathrm{H} / \mathrm{C}=$ Hyperglycaemic control, ECE $=$ Eleusine coracana extract, TC $=$ Total cholesterol, $\mathrm{LDL}=\mathrm{Low}$ density lipoprotein, $\mathrm{TG}=$ Triglyceride, $\mathrm{HDL}=$ High density lipoprotein. 


\section{CONCLUSION}

The results obtained revealed that ethanol leaf extract of Eleusine coracana possesses antihyperglycaemic and antihyperlipidaemic activities in alloxan-induced hyperglycaemic rats. This gives scientific basis for the traditional claim of its use against diabetes mellitus.

\section{CONFLICT OF INTEREST}

The authors have no conflicting interests to disclose.

\section{ACKNOWLEDGMENT}

The authors are grateful for the support of the technical staff of Department of Pharmacology and Therapeutics, Bayero University, Kano and Ahmadu Bello University, Zaria.

\section{REFERENCES}

Al-Logmani AS, Zari TA. Effects of Nigella sativa L. and Cinnamomum zeylanicum Blume oils on some physiological parameters in streptozotocin-induced diabetic rats; Bol. Latinoam Caribe. Plant Med Aromat, 2009; 8:86-96.

Al-Shamaony L, Al-Khazraji SM, Twaij HAA. Hypoglycaemic effect of Artemisia herba alba. II. Effect of a valuable extract on some blood parameters in diabetic animals. J Ethnopharmacol, 1994; 43:167-171.

Balamurugan K, Nishanthini A, Mohan VR. Antidiabetic and antihyperlipidaemic activity of ethanol extract of Melastoma malabathricum Linn. leaf in alloxan induced diabetic rats. Asian Pac J Trop Biomed, 2014; 4(1):442-448.

Beach EF, Turner JJ. An enzymatic method for glucose determination uptake in body fluids. Clin Chem, 1958; 4(6):462-475.

Burkill HM. 1985. The useful plants of west tropical Africa United Kingdom: Royal Botanic Gardens, Kew, Vol. 2.

Chandrashekar A. Finger Millet: Eleusine coracana. Adv Food Nutr Res, 2010; 59:215-262.

Cragg GM, Newman DJ. Natural products: a continuing source of novel drug leads. Biochim Biophys Acta, 2013; 1830(6):3670-3695.

Czinner E, Hagymasi K, Blazovics A, Kery A, Szoke E, Lemverkovics E. In vitro antioxidant properties of Helichrysum arenarium (L.) Moench. J Ethnopharmacol, 2000; 6(73):437-443.

Devi PB, Vijayabharathi R, Sathyabama S, Malleshi NG, Priyadarisini VB. Health benefits of finger millet (Eleusine coracana L.) polyphenols and dietary fiber: a review. J Food Sci Technol, 2011; 51(6):1021-1040

Evans WC. 2009. Trease and Evans' Pharmacognosy. $16^{\text {th }}$ ed. London, U.K: Elsevier Health Sciences 135-144.

Goldner MG, Gomori G. Studies on mechanism of alloxan diabetes. Endocrinology, 1944; 35(4):241-248.

Hegde PS, Rajasekaran, NS, Chandra TS. Effects of the antioxidant properties of millet species on oxidative stress and glycemic status in alloxan-induced diabetic rats. Nutr Res, 2005; 25:1109-1120.

Hellmuth E, Damm P, Molsted-Pedersen L. Oral hypoglycaemic agents in 118 pregnancies. Diabet Med, 2000; 17(7):507-511.

Jadeja RN, Thounaojam MC, Devkar RV, Ramachandran AV. Clerodendron glandulosum Coleb. Verbenaceae, ameliorates high fat diet-induced alteration in lipid and cholesterol metabolism in rats. Braz J Pharmacog, 2010; 20(1):117-123.
Lee HJ, Jeong KH, Kim YG, Moon JY, Lee SH, Ihm CG, Sung JY, Lee TW. Febuxostat ameliorates diabetic renal injury in a streptozotocininduced diabetic rat model. Am J Nephrol, 2014; 40(1):56-63.

Leeds JS, Forman EM, Morley S, Scott AR, Tesfaye S, Sanders DS. Abnormal liver function tests in patients with Type 1 diabetes mellitus: prevalence, clinical correlations and underlying pathologies. Diabet Med, 2009; 26(12):1235-1241.

Lenz S. The mechanisms of alloxan- and streptozotocin-induced diabetes. Diabetologia, 2008; 51:216-226.

Lorke D. A new approach to practical acute toxicity testing. Arch Toxicol, 1983; 54:275-287.

Lu FC. 1996. Basic toxicology: Fundamentals, Target Organs and Risk Assessment, 3rd ed, Taylor and Francis, New York, USA: Hemisphere Publishing Company.

Mamun-or-Rashid ANM, Hossain S, Hassan N, Dash BK, Sapon A, Kumer M. A review on medicinal plants with antidiabetic activity. J Pharmacog Phytochem, 2014; 3(4):149-159.

National Research Council. 1996. Guide for the Care and Use of Laboratory Animals. Washington DC, U.S.:The National Academies Press.

Ojiako OA, Chikezie PC, Ogbuji AC. Blood glucose level and lipid profile of alloxan-induced hyperglycaemic rats treated with single and combinatorial herbal formulations. J Trad Compl Med, 2016; 6:184-192.

Ramírez-Espinosa JJ, Rios MY, López-Martínez S, LópezVallejo F, Medina-Franco JL, Paoli P, Camici G, Navarrete-Vázquez G, Ortiz-Andrade R, Estrada-Soto S. Antidiabetic activity of some pentacyclic acid triterpenoids, role of PTP-1B: in vitro, in silico, and in vivo approaches. Eur J Med Chem, 2011; 46(6):2243-2251.

Scalbert A, Manach C, Morand C. Dietary phenols and prevention of diseases. J Food Sci Nutr, 2005; 9(45):467-473.

Shobana S, Mysore R, Kalpana P, Krishnapura S, Nagappa G, Amelioration of hyperglycaemia and its associated complications by finger millet (Eleusine coracana) seed coat matter in streptozotocin induced diabetic rats. Br J Nutr, 2009; 9(104):1787-1795.

Spencer EA, Pirie KL, Stevens RJ. Diabetes and modifiable risk factors for cardiovascular disease: the prospective Million Women Study. Eur J Epidemiol, 2008; 23:793-799.

Subramanian S, Chait A. Hypertriglyceridemia secondary to obesity and diabetes. Biochim Biophys Acta, 2012; 1821:819-825.

Trivedi NA, Myumber B, Bhart JB, Hermavathik KG. Effect of Shilagit on blood glucose and lipid profile in alloxan-induced diabetic rats. Indian J Pharmacol, 2004; 36:373-376.

Tsuda T, Horio F, Uchida K, Aoki H, Osawa T. Dietary cyanadin 3-o- $\beta$-D-glucoside-rich purple corn color prevents obesity and ameliorates hyperglycaemia in mice. J Nutr, 2003; 133:2125-2130

Viswanath V, Urooj A, Malleshi NG. Evaluation of antioxidant and antimicrobial properties of finger millet polyphenols (Eleusine coracana). Food Chem, 2009; 114:340-346.

World Health Organization (WHO). Global report on diabetes. Fact Sheet, Geneva. 2016.

\section{How to cite this article:}

Yaro AH, Aliyu M, Borodo SB, Nazifi AB. Antihyperglycaemic and Antihyperlipidaemic Activities of Ethanol Leaf Extract of Eleusine coracana (Linn.) Gaertn. in Alloxan-Induced Hyperglycaemic Rats. J App Pharm Sci, 2018; 8(07): 028-032. 